\title{
Targeting the COX-2 Pathway to Improve Therapeutic Response in the Obese Breast Cancer Patient Population
}

\author{
Laura W. Bowers ${ }^{1} \cdot$ Linda A. deGraffenried ${ }^{1}$
}

Published online: 22 April 2015

(C) Springer International Publishing AG 2015

\begin{abstract}
Multiple studies have demonstrated that obesity is associated with a worse outcome for all breast cancer subtypes and that obese breast cancer patients do not respond as well as normal weight patients to aromatase inhibitor treatment and chemotherapy. While a number of mechanisms have been proposed to explain this link, recent studies have provided evidence that elevated local cyclooxygenase-2 (COX-2) expression and the resulting increase in prostaglandin E2 (PGE2) production may play an important role. COX-2 upregulation in breast tumors is associated with a poor prognosis, a connection generally attributed to PGE2's direct effects on apoptosis and invasion as well as its stimulation of preadipocyte aromatase expression and subsequent estrogen production. Research in this area has provided a strong foundation for the hypothesis that COX-2 signaling is involved in the obesity-breast cancer link, and further study regarding the role of COX-2 in this link is warranted.
\end{abstract}

Keywords Breast cancer · Obesity · Cyclooxygenase-2 . Prostaglandin E2

\section{Introduction}

Over the past 30 years, obesity has become a significant global health problem. In the USA, the adult obesity rate has risen

This article is part of the Topical Collection on Cancer Chemoprevention

Linda A. deGraffenried

degraffenried@austin.utexas.edu

1 Department of Nutritional Sciences, University of Texas at Austin, 1400 Barbara Jordan Boulevard, R1800, Austin, TX 78723, USA over that time period to a current rate of $35.7 \%$ [1], and similar trends are evident worldwide [2]. Given the association between excess adiposity and an increased incidence of and mortality from numerous chronic diseases, this elevation in obesity rates presents a serious threat to public health. In addition to promoting the development of cardiovascular disease, diabetes mellitus, and hypertension, obesity has been shown to enhance the risk and progression of several types of cancer, including breast cancer.

In postmenopausal women, obesity increases breast cancer risk by approximately $40 \%$ [3-5]. While most research has indicated that obesity actually protects premenopausal women from breast cancer, a recent study suggests that the interaction may be more complex, differing with the presence of other risk factors [6, 7]. A large body of evidence has established that obesity is also associated with a worse breast cancer prognosis for both pre- and postmenopausal women. One prospective study found that the breast cancer mortality rate escalates with each successive increase in BMI category [8]. Another study showed a significantly greater risk for disease recurrence within 10 years of diagnosis in breast cancer patients who were obese at the time of treatment in comparison to nonobese patients [9]. These effects could be due to later diagnosis in the obese population, resulting in more advanced disease at the time of diagnosis. However, while Majed et al. [10] reported that the obese patients from a large cohort followed for 20 years presented with more advanced tumors, suggesting that diagnosis had been delayed, the authors ultimately found that multivariate statistical analysis demonstrated an independent effect of obesity on breast cancer prognosis. Survival analysis revealed increased metastatic recurrence as well as decreased disease-free interval and overall survival in the obese patient population. Additional studies have produced similar findings, supporting the link between obesity and a worse prognosis $[11 \cdot, 12]$. 
A number of mechanisms have been proposed to explain this obesity-breast cancer connection, including abnormalities in the circulating levels of estrogens, insulin, insulin-like growth factor, leptin, adiponectin, vascular regulators, and inflammatory cytokines [13]. However, exploration of these signaling molecules has thus far not produced any improvement in the treatment regimen for obese breast cancer patients. Recent studies suggesting the cyclooxygenase 2 (COX-2) enzyme may be an important mediator of the obesity-breast cancer link have sparked interest in this pathway as a potential druggable target for the obese patient population. Here, we review the evidence regarding the hypothesis that COX-2 plays a significant role in obesity-associated breast cancer progression and examine whether its inhibition may improve obese patient outcome.

\section{COX-2 and Breast Cancer Progression}

Most healthy tissues do not express detectable levels of COX2 , the enzyme responsible for catalyzing the conversion of arachidonic acid into a number of different prostanoids. However, it can be highly induced in several tissue types as part of the inflammatory response and is thus a key pharmaceutical target for the reduction of pain and inflammation [14]. Upregulation of this protein has also been found in many human cancers, including $40 \%$ of breast tumors [15]. Of the prostanoids, the pro-inflammatory prostaglandin E2 (PGE2) is found in the highest concentrations within breast tumor tissue and is known to promote breast cancer progression [16]. Consequently, it is not surprising that high COX-2 expression levels have been found to be correlated with a poor breast cancer outcome. Ristimäki et al. [17] demonstrated that elevated COX-2 expression in invasive breast tumors was associated with decreased distant tumor-free survival as well as various negative prognostic indicators, including a larger tumor size, higher histological grade and proliferation rate, negative hormone receptor status, and the presence of axillary metastases. Another research group reporting a link between high COX-2 expression in stage I-III breast tumors and a lower survival rate found that this was independent of tumor size and grade as well as estrogen receptor alpha (ER $\alpha)$, HER2, and nodal status [18]. COX-2 positivity was similarly correlated with a $35 \%$ increase in the risk of breast cancer death in a study of stage I-IV breast tumors, but this difference in risk was no longer statistically significant after adjustment for tumor stage at diagnosis [19]. Park et al. [20] also found an association between COX-2 status and a worse breast cancer survival, but only in proliferative breast tumors. Despite these variations in results, which may be due to differences in study population, methodology, and patient subset risk, the preponderance of the evidence supports the premise that elevated COX-2 expression is linked to a worse breast cancer outcome.
Animal model and cell culture experiments provide further data, suggesting that COX-2 upregulation can promote breast cancer progression. They also demonstrate that this effect is mediated by inhibition of apoptosis as well as stimulation of cell migration, invasion, and possibly proliferation. For example, overexpression of COX-2 in the mammary gland has been shown to be sufficient to induce the development of mammary tumors in mice, and these tumors exhibit an anti-apoptotic protein expression profile [21]. Another study found that treatment with the COX-2 inhibitor celecoxib arrested the growth of MDA-MB-231 breast cancer cells in vitro via the induction of apoptosis. In a xenograft mouse model using the same cells, inhibition of tumor growth with celecoxib treatment was accompanied by less vascularization and greater tumor necrosis [22]. COX-2 has also been strongly linked to greater breast cancer cell metastatic capability. In one study, COX-2 overexpression enhanced the ability of MDA-435S breast cancer cells to metastasize to the bones of nude mice, while inhibition of COX-2 reduced bone metastasis burden [23]. The role of COX-2 in promoting breast cancer metastasis is further supported by a study showing that a fibroblast-induced increase in invasive capacity in a xenograft model of human DCIS was reversed with COX-2 inhibitor treatment [24]. Cell culture studies have also demonstrated that COX-2 overexpression in MDA-MB-231 cells leads to an increase in cell migration and invasion [25]. In contrast, while PGE2 induces proliferation in both colon and lung cancer cells [26, 27], its effect on breast cancer cell proliferation is unclear. Several studies have concluded that PGE2 does stimulate breast cancer cell proliferation based on the ability of COX-2 inhibitors to suppress proliferation in these cells [28, 29]. However, Robertson et al. [30] reported no increase in MDA-MB-231 cell proliferation following PGE2 treatment. Indirectly, PGE2 may promote the proliferation of ER $\alpha$-positive breast cancer cells by stimulating pre-adipocyte aromatase expression and the subsequent production of estradiol within breast tissue adjacent to the tumor [31]. Previous pre-clinical studies have demonstrated that PGE2, derived from macrophages and other sources, is a potent stimulant of pre-adipocyte aromatase expression [32, 33]. Together, these studies provide a large body of evidence supporting COX-2's ability to promote breast cancer progression via multiple mechanisms (Fig. 1).

\section{Obesity and COX-2 Expression}

While obesity has been shown to negatively impact breast cancer outcome for all tumor subtypes in both pre- and postmenopausal patients, the most prominent effects are seen in ER $\alpha$-positive postmenopausal patients, a finding confirmed by a recent retrospective analysis of the German BRENDA cohort [34]. Obesity has been hypothesized to negatively impact outcomes in this patient population by promoting adipose 


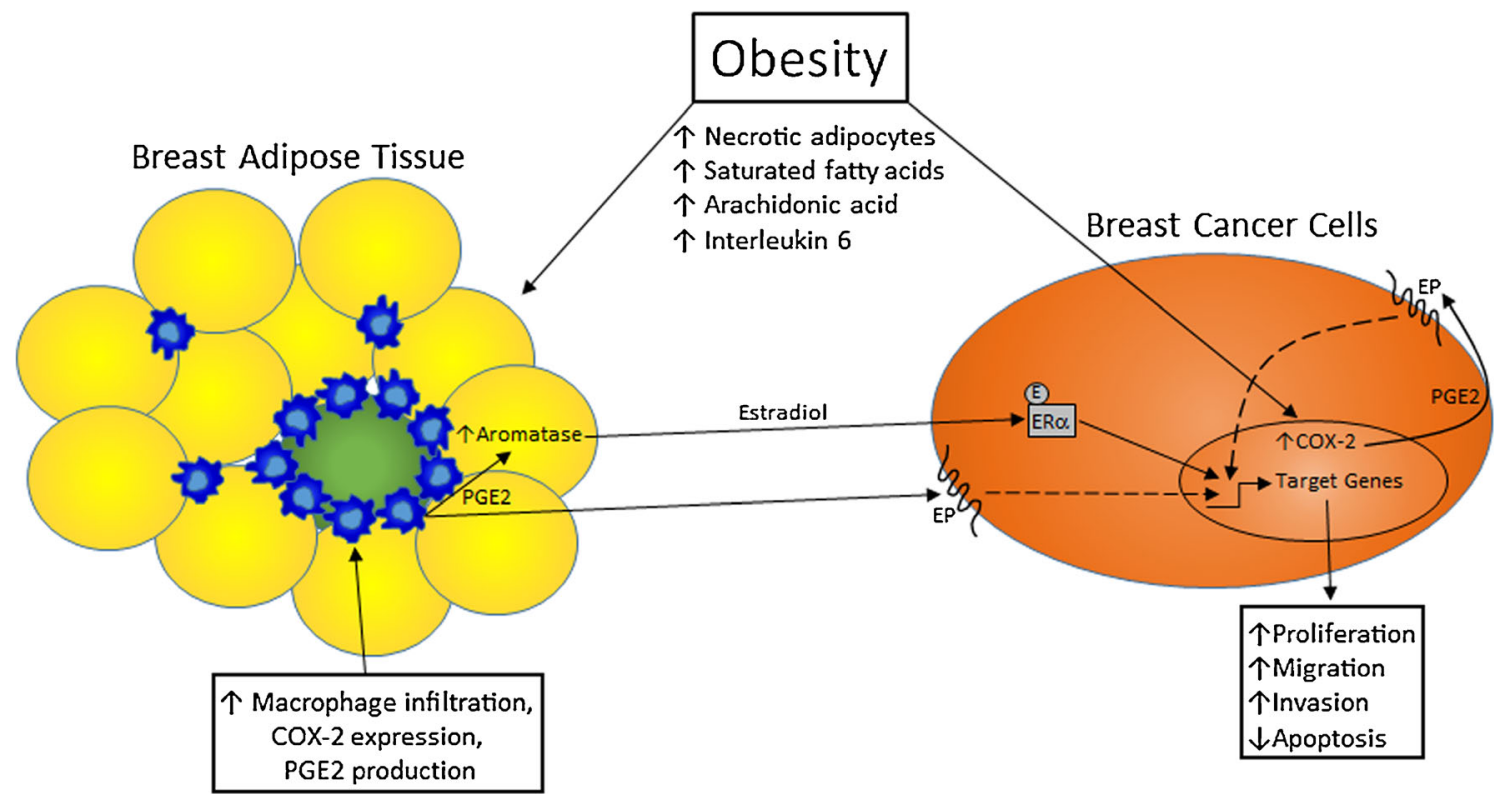

Fig. 1 Obesity, COX-2 expression, and breast cancer progression. Obesity stimulates local COX-2 expression in the breast through multiple mechanisms, leading to increased PGE2 production that directly and indirectly promotes breast cancer progression. With the increase in adipocyte necrosis that typically accompanies obesity, there is a rise in macrophage infiltration into the breast adipose tissue. COX-2 expression in these macrophages is enhanced by an obesity-associated elevation in circulating saturated fatty acid levels, which are the result of a higher rate of lipolysis. In addition, circulating interleukin-6 levels are typically

tissue expression of aromatase, the rate-limiting enzyme in the production of estradiol from testosterone. Due to an abundance of this aromatase-expressing tissue, obese postmenopausal women typically have higher levels of circulating estradiol [35-37], and researchers have posited that this may contribute to the observed increase in breast cancer risk. However, aromatase expression in breast tumors and their associated adipose tissue is typically five-fold higher than the levels found in disease-free breast tissue, and this is accompanied by a ten-fold elevation in estradiol concentration in comparison to serum levels [38]. This suggests that increased circulating estradiol is likely not a contributor to obesity-induced breast cancer progression, but enhanced local aromatase expression and estradiol production may be playing a role

Recent studies by Dannenberg and colleagues confirmed the presence of elevated aromatase expression in the breast tissue of overweight and obese women with and without breast cancer. They also demonstrated high congruence between obesity and local breast tissue aromatase levels and inflammation, the latter measured by the number of crownlike structures (CLS-B). CLS-B are inflammatory foci within the breast adipose tissue that are composed of a necrotic adipocyte surrounded by macrophages, which can express high levels of COX-2. In fact, breast tissue inflammation and aromatase expression were also positively correlated with levels COX-2 and PGE2 [39••, 40]. elevated with obesity, and this may induce greater breast cancer cell COX-2 expression. PGE2 production by both cell types may also be increased with obesity by higher serum arachidonic acid levels. This PGE2 can directly stimulate migration and invasion and inhibit apoptosis in breast cancer cells. It can also indirectly affect breast cancer cell proliferation, migration, and apoptosis via its induction of pre-adipocyte aromatase expression and estradiol production. COX-2 cyclooxygenase-2, $E$ estradiol, $E P$ prostaglandin receptor, $E R \alpha$ estrogen receptor alpha, $P G E 2$ prostaglandin E2

In addition to promoting the incidence of these CLS-B, obesity is associated with other factors that may further increase COX-2 levels in adipose-infiltrating macrophages. Saturated fatty acids can stimulate COX-2 expression and PGE2 secretion by cultured macrophages [32, 41], and the increased lipolysis that occurs with obesity results in a higher concentration of circulating free fatty acids [42-44]. Consequently, the obesity-associated elevation in breast tissue aromatase levels may also be due to free fatty acid-induced macrophage COX-2 expression. Obesity is also typically accompanied by increased circulating levels of several cytokines that may further enhance local COX-2 expression. For example, serum concentrations of IL- 6 and TNF- $\alpha$ are generally increased with obesity [45], and these cytokines have been shown to promote PGE2 production in multiple cell types via their effects on COX-2 expression [46, 47].

Our recent findings support the possibility that higher concentrations of circulating saturated fatty acids and/or cytokines may promote greater macrophage COX-2 expression in the breast tissue of obese women. We demonstrated that cultured macrophages exposed to sera from obese postmenopausal women expressed higher levels of COX-2 mRNA and produced more PGE2 in comparison to cells cultured in sera from normal weight women, and the obese patient sera contained higher concentrations of saturated fatty acids, interleukin-6, and tumor necrosis factor-alpha $[48 \bullet, 49]$. Through a series 
of direct and indirect co-culture experiments, we found that this obese patient sera-induced elevation in macrophage COX-2 expression and PGE2 production could stimulate increased adipocyte aromatase expression, resulting in greater breast cancer cell ER $\alpha$ activity, proliferation, and migration [48•]. These results suggest that increased local COX-2 and aromatase expression could be a significant contributor to the worse outcome observed in obese postmenopausal patients with $\mathrm{ER} \alpha$-positive breast cancer.

To our knowledge, no one has published data regarding the impact of obesity on breast cancer epithelial cell COX-2 expression in humans. However, in vitro studies from our laboratory indicate that exposure to sera from obese women promotes greater breast cancer cell COX-2 expression and PGE2 production in comparison to normal weight patient sera [50]. In addition, Stephen Hursting's laboratory has found that dietinduced obesity promotes mammary tumor growth and higher tumor COX-2 expression and PGE2 levels in a xenograft model, utilizing two mammary tumor cell lines isolated from the MMTV-Wnt-1 transgenic mouse (personal communication). Together, this data strongly suggests that obesity may induce higher breast tumor COX-2 expression in vivo. Given the association between elevated breast tumor COX-2 levels and poor prognosis, further examination of the impact of obesity on breast tumor COX-2 expression is warranted.

\section{NSAID Use and Breast Cancer Progression}

Non-steroidal anti-inflammatory drugs (NSAIDs) are taken daily by many individuals for a variety of reasons, including cardiovascular disease prevention and pain relief. This group of drugs, which include aspirin, ibuprofen, and naproxene, specifically targets COX-2 and inhibits multiple inflammatory pathways. The link between an elevated COX-2 expression and poor breast cancer prognosis has thus spurred great interest in determining whether NSAID use is associated with a better patient outcome. With the increasing evidence that both macrophage and breast cancer cell COX-2 expression may be significant mediators of obesity-associated breast cancer progression, the impact of NSAID use on the obese breast cancer patient population should be specifically assessed. We recently demonstrated that daily NSAID use in patients with invasive $\mathrm{ER} \alpha$-positive breast cancer receiving adjuvant endocrine therapy was correlated with a $52 \%$ lower recurrence rate. NSAID users in this patient population also remained disease-free for more than 2 years longer than non-users [48•]. Some much larger prospective studies examining NSAID use following breast cancer diagnosis have also shown positive associations with various measures of disease outcome, but to our knowledge, only one has reported a variance of similar magnitude [51]. We hypothesized that our results may be attributable to the overwhelming incidence of overweight and obesity in our patient population, which had an average body mass index (BMI) of $31 \mathrm{~kg} / \mathrm{m}^{2}$. This hypothesis is supported by our cell culture experiments, demonstrating that sera from obese postmenopausal women stimulate higher macrophage and breast cancer cell COX-2 expression and PGE2 production in comparison to cells cultured in sera from normal weight women, as discussed above.

Cumulatively, other studies that have examined the impact of NSAID use on breast cancer patient outcome appear to indicate that it may be an effective addition to adjuvant breast cancer treatment, regardless of BMI, ER $\alpha$, or menopausal status (Table 1). However, the variability in design and patient population among these studies makes any comparison to our results difficult. In an examination of stage I-III breast cancer patients from the Nurses' Health Study, aspirin use 6-7 days/ week was associated with a significant reduction in the risk of distant recurrence (RR, 0.57; $95 \% \mathrm{CI}, 0.39-0.82$ ), and stratification of the subjects by BMI, menopausal status, and ER $\alpha$ status did not alter this result [51]. Blair et al. [52] reported that any amount of regular NSAID use was correlated with a lower risk of breast cancer death (HR, 0.64; $95 \% \mathrm{CI}, 0.39-1.05)$ in postmenopausal patients. Adjustment for BMI category did not change this association, but its statistical significance was reduced by adjustment for ER $\alpha$ status. Another study specifically examining the post-diagnostic use of COX-2 inhibitors found that incidence of bone metastases was significantly reduced among users (OR, 0.11; $95 \%$ CI, 0.02-0.88) [53]. In contrast with these studies, ibuprofen (RR, 0.56; $95 \%$ CI, 0.32-0.98), but not aspirin (RR, 1.09; $95 \%$ CI, 0.74 1.61 ), use $\geq 3$ days/week reduced the recurrence rate in a population of pre- and postmenopausal breast cancer patients [54], and these results did not change after controlling for BMI, menopausal status, and ER $\alpha$.

Despite the lack of change in these studies' results with adjustment for or stratification by BMI category, the evidence from our research suggests that overweight and obese breast cancer patients may derive the greatest benefit from NSAID use. The patient population in our study was also largely postmenopausal and included only hormone-responsive patients. Because obesity is associated with higher COX-2 and PGE2 levels and aromatase expression in female breast tissue [39••, 40], it seems likely that the efficacy of NSAIDs in a postmenopausal, ER $\alpha$-positive patient population would increase with greater adiposity. In this population, the addition of daily NSAID use to aromatase inhibitor treatment may improve response to the endocrine therapy by reducing production of aromatase-promoting PGE2. In fact, NSAID use in postmenopausal women has been shown to be correlated with significantly lower serum estradiol levels after adjusting for age and BMI [55]. Perhaps, the lack of variation in effect among BMI categories in previous studies of NSAID is due to their failure to stratify the data by BMI, ER $\alpha$, and menopausal status simultaneously. This question could potentially be addressed by 







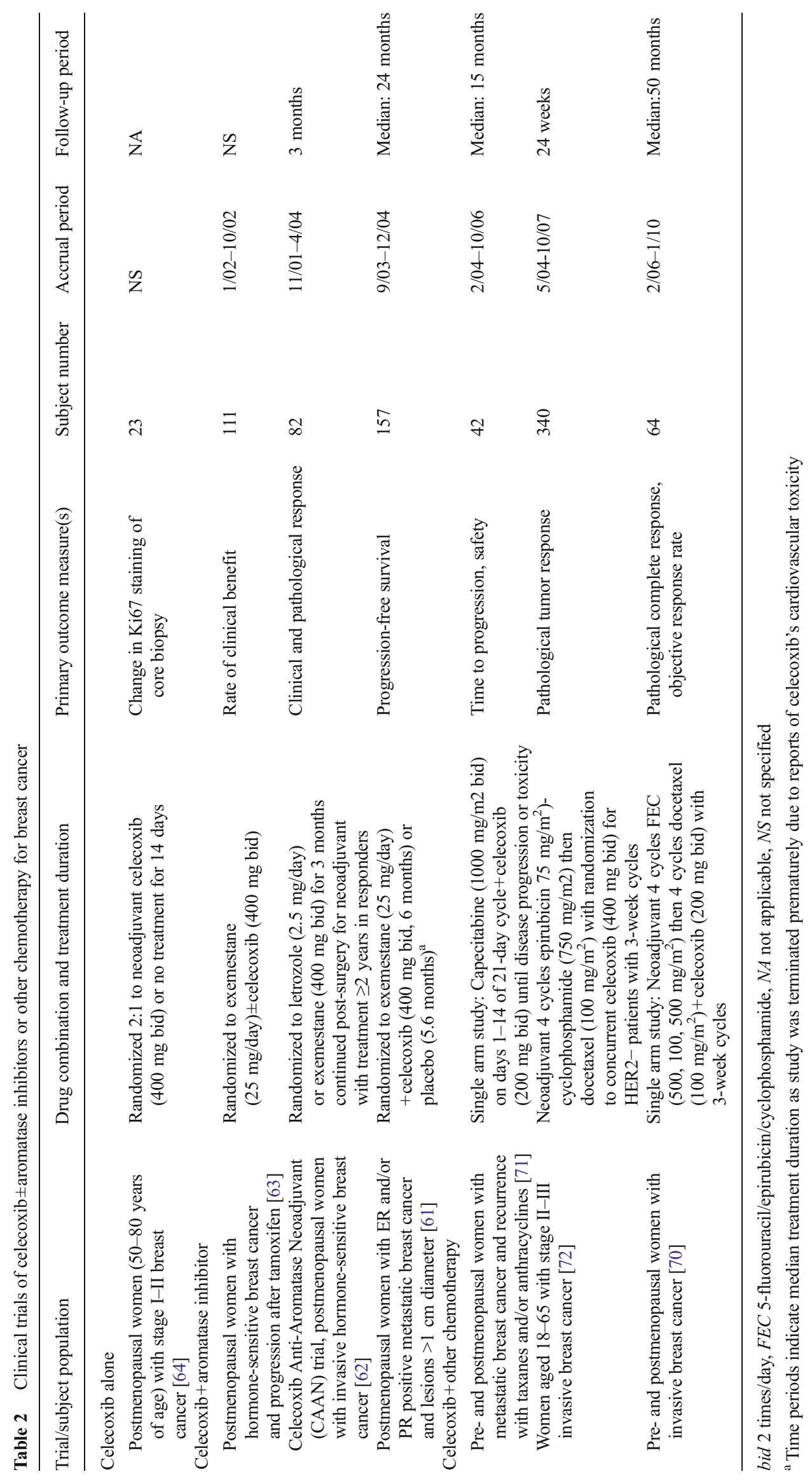


benefit by BMI category, so it is impossible to determine from this data whether overweight/obese women in this patient population are more likely to benefit from COX-2 inhibition. To our knowledge, no one has examined the efficacy of a COX-2 inhibitor/aromatase inhibitor combination in animal models of obesity and mammary carcinogenesis either.

Given that elevated COX-2 expression and PGE2 production have direct breast cancer promoting effects independent of their impact on aromatase expression, a few researchers have also conducted clinical trials to examine the benefit of COX-2 inhibitor treatment in combination with chemotherapy. Several studies have linked an elevated BMI with a poor response to chemotherapy, indicating a need for the development of more effective chemotherapeutic regimens for this patient population. For example, Del Fabbro et al. [65] found that overweight $\left(\mathrm{BMI} \geq 25 \mathrm{~kg} / \mathrm{m}^{2}\right)$ patients receiving neoadjuvant chemotherapy had a lower pathological complete response (pCR) and shorter progression-free survival in comparison to normal weight patients. Others have demonstrated a similar correlation between overweight status and a decreased chance of achieving pCR with neoadjuvant chemotherapy $[66,67]$. These results are supported by reports that obesity is associated with a worse breast cancer outcome, including lower disease-free survival and overall survival for all breast cancer subtypes treated with taxane agents $[68,69]$. These findings, in conjunction with the data indicating an association between obesity and higher breast tissue COX-2 expression, suggest that obese patients could be particularly responsive to a COX-2 inhibitor/chemotherapy combination.

Collectively, clinical trials assessing the effects of this type of drug combination on breast cancer have found that various COX-2 inhibitor/chemotherapy regimens are effective and safe, but may not provide further benefit over chemotherapy alone (Table 2). One phase II study examining the addition of concurrent celecoxib to a neoadjuvant regimen of 5-fluorouracil, epirubicin, and cyclophosphamide (FEC) followed by docetaxel demonstrated that the COX-2 inhibitor was welltolerated and $80 \%$ of the invasive breast cancer patients receiving this combination were disease-free at a 50-month follow-up [70]. Fabi et al. [71] also found that metastatic breast cancer patients pre-treated with anthracyclines and/or taxanes tolerated a combination treatment of capecitabine and celecoxib with little toxicity and a $47.5 \%$ clinical benefit rate defined as CR plus stable disease of $\geq 6$ months. Patients with tumor overexpression of COX-2 had a significantly longer time to progression and overall survival. Unfortunately, neither of these studies included an arm without celecoxib, so the authors could not conclude whether the inclusion of celecoxib in the chemotherapeutic regimen improved patient outcome. To our knowledge, only one study has been conducted of a celecoxib/chemotherapy combination that included an arm without celecoxib. This study assessed the benefit of epirubicin/cyclophosphamide followed by docetaxel with randomization to concurrent celecoxib (HER2- patients) or trastuzumab (HER $2+$ patients) in stage II-III patients. There was no significant difference in pCR between the HER2patients that did $(13 \%)$ and did not $(11.5 \%)$ receive celecoxib, and the authors concluded that the addition of celecoxib to this drug regimen was unlikely to improve prognosis in this patient population [72].

As with the clinical trials of celecoxib/aromatase inhibitor combination treatments, there is no indication that the authors of these studies stratified their data by BMI category to analyze whether obese patients derived greater clinical benefit from the addition of celecoxib. However, Stephen Hursting's laboratory has demonstrated that the tumor-promoting effects of diet-induced obesity were significantly reduced by omega 3 ethyl ester (Lovaza ${ }^{\mathrm{TM}}$, GlaxoSmithKline, UK) treatment in a xenograft model utilizing two mammary tumor cell lines derived from the MMTV-Wnt-1 transgenic mouse. Lovaza supplementation in the obese mice was also associated with lower mammary tumor COX-2 expression and PGE2 levels (personal communication). Given that the molecular profiles of the two cell lines used (one basal-like and one claudin low) indicate that these tumors were estrogen-independent, these results suggest that the anti-tumor effects of Lovaza may be mediated by its suppression of COX-2, but not any subsequent reduction in aromatase expression. Consequently, we propose that obese breast cancer patients may benefit from the addition of treatments targeting the COX-2 pathway, regardless of their ER $\alpha$ status.

\section{Conclusion}

Obesity is known to be associated with a worse breast cancer prognosis as well as reduced response to aromatase inhibitors and chemotherapy. While the mechanism(s) mediating these effects are not completely understood, evidence from our laboratory and others suggests that increased COX-2 expression in tumor epithelial cells and local adipose-infiltrating macrophages could be playing an important role in the link between obesity and breast cancer progression. However, no clinical trial of COX-2 inhibitor treatment for breast cancer has specifically assessed its efficacy in obese patients. Additional research to examine the benefit of combining a COX-2 targeting drug with endocrine treatment and/or chemotherapy in this patient population is thus warranted.

Acknowledgments LB is currently supported by a grant from the National Cancer Institute (R25CA057726) and was previously supported by a Predoctoral Traineeship Award from the US Department of Defense, Breast Cancer Research Program (BCRP) of the Congressionally Directed Medical Research Programs (CDMRP) (W81XWH-11-1-0132).

\section{Compliance with Ethics Guidelines}


Conflict of Interest Laura W. Bowers and Linda A. deGraffenried declare that they have no conflict of interest.

Human and Animal Rights and Informed Consent This article does not contain any studies with human or animal subjects performed by any of the authors.

\section{References}

Papers of particular interest, published recently, have been highlighted as:

- Of importance

-• Of major importance

1. Flegal KM, Carroll MD, Kit BK, Ogden CL. Prevalence of obesity and trends in the distribution of body mass index among US adults, 1999-2010. JAMA. 2012;307:491-7.

2. World Health Organization. World Health Statistics 2012. http:// www.who.int/gho/publications/world health statistics/2012/en/. Accessed 5 September 2014.

3. Phipps AI, Chlebowski RT, Prentice R, McTiernan A, Stefanick ML, Wactawski-Wende J, et al. Body size, physical activity, and risk of triple-negative and estrogen receptor-positive breast cancer. Cancer Epidemiol Biomarkers Prev. 2011;20:454-63.

4. Key TJ, Appleby PN, Reeves GK, Roddam A, Dorgan JF, Longcope C, et al. Endogenous Hormones Breast Cancer Collaborative Group. Body mass index, serum sex hormones, and breast cancer risk in postmenopausal women. J Natl Cancer Inst. 2003;95:1218-26

5. Trentham-Dietz A, Newcomb PA, Storer BE, Longnecker MP, Baron J, Greenberg ER, et al. Body size and risk of breast cancer. Am J Epidemiol. 1997;145:1011-9.

6. Anderson GL, Neuhouser ML. Obesity and the risk for premenopausal and postmenopausal breast cancer. Cancer Prev Res. 2012;5: 515-21.

7. Cecchini RS, Costantino JP, Cauley JA, Cronin WM, Wickerham DL, Land SR, et al. Body mass index and the risk for developing invasive breast cancer among high-risk women in NSABP P-1 and STAR breast cancer prevention trials. Cancer Prev Res. 2012;5: 583-92.

8. Calle EE, Rodriguez C, Walker-Thurmond K, Thun MJ. Overweight, obesity, and mortality from cancer in a prospectively studied cohort of U.S. adults. N Engl J Med. 2003;348:1625-38.

9. Senie RT, Rosen PP, Rhodes P, Lesser ML, Kinne DW. Obesity at diagnosis of breast carcinoma influences duration of disease-free survival. Ann Intern Med. 1992;116:26-32.

10. Majed B, Moreau T, Senouci K, Salmon RJ, Fourquet A, Asselain B. Is obesity an independent prognosis factor in woman breast cancer? Breast Cancer Res Treat. 2008;111:329-42.

11. Protani M, Coory M, Martin JH. Effect of obesity on survival of women with breast cancer: systematic review and meta-analysis. Breast Cancer Res Treat. 2010;123:627-35. This meta-analysis of 43 studies constitutes an important contribution to the literature, as it demonstrates that the preponderance of the evidence indicates that obesity is associated with a worse breast cancer outcome in women of all ages.

12. Chlebowski RT, Aiello E, McTiernan A. Weight loss in breast cancer patient management. J Clin Oncol. 2002;20:1128-43.

13. Ford NA, Devlin KL, Lashinger LM, Hursting SD. Deconvoluting the obesity and breast cancer link: secretome, soil and seed interactions. J Mammary Gland Biol Neoplasia. 2013;18:267-75.
14. Dubois RN, Abramson SB, Crofford L, Gupta RA, Simon LS, Van De Putte LB, et al. Cyclooxygenase in biology and disease. FASEB J. 1998;12:1063-73.

15. Howe LR. Inflammation and breast cancer. Cyclooxygenase/ prostaglandin signaling and breast cancer. Breast Cancer Res. 2007;9:210

16. Wang D, Dubois RN. Cyclooxygenase-2: a potential target in breast cancer. Semin Oncol. 2004;31:64-73.

17. Ristimaki A, Sivula A, Lundin J, Lundin M, Salminen T, Haglund C, et al. Prognostic significance of elevated cyclooxygenase-2 expression in breast cancer. Cancer Res. 2002;62:632-5.

18. Zerkowski MP, Camp RL, Burtness BA, Rimm DL, Chung GG. Quantitative analysis of breast cancer tissue microarrays shows high cox-2 expression is associated with poor outcome. Cancer Investig. 2007:25:19-26.

19. Holmes MD, Chen WY, Schnitt SJ, Collins L, Colditz GA, Hankinson SE, et al. COX-2 expression predicts worse breast cancer prognosis and does not modify the association with aspirin. Breast Cancer Res Treat. 2011;130:657-62.

20. Park BW, Park S, Park HS, Koo JS, Yang WI, Lee JS, et al. Cyclooxygenase-2 expression in proliferative $\mathrm{Ki}$-67-positive breast cancers is associated with poor outcomes. Breast Cancer Res Treat. 2012;133:741-51.

21. Liu CH, Chang SH, Narko K, Trifan OC, Wu MT, Smith E, et al. Overexpression of cyclooxygenase- 2 is sufficient to induce tumorigenesis in transgenic mice. J Biol Chem. 2001;276:18563-9.

22. Basu GD, Pathangey LB, Tinder TL, Gendler SJ, Mukherjee P. Mechanisms underlying the growth inhibitory effects of the cyclooxygenase- 2 inhibitor celecoxib in human breast cancer cells. Breast Cancer Res. 2005;7:R422-35.

23. Singh B, Berry JA, Shoher A, Ayers GD, Wei C, Lucci A. COX-2 involvement in breast cancer metastasis to bone. Oncogene. 2007;26:3789-96.

24. Hu M, Peluffo G, Chen H, Gelman R, Schnitt S, Polyak K. Role of COX-2 in epithelial-stromal cell interactions and progression of ductal carcinoma in situ of the breast. Proc Natl Acad Sci U S A. 2009; 106:3372-7.

25. Singh B, Berry JA, Shoher A, Ramakrishnan V, Lucci A. COX-2 overexpression increases motility and invasion of breast cancer cells. Int J Oncol. 2005;26:1393-9.

26. Krysan K, Reckamp KL, Dalwadi H, Sharma S, Rozengurt E, Dohadwala M, et al. Prostaglandin E2 activates mitogen-activated protein kinase/Erk pathway signaling and cell proliferation in nonsmall cell lung cancer cells in an epidermal growth factor receptorindependent manner. Cancer Res. 2005;65:6275-81.

27. Wang D, Buchanan FG, Wang H, Dey SK, DuBois RN. Prostaglandin E2 enhances intestinal adenoma growth via activation of the Ras-mitogen-activated protein kinase cascade. Cancer Res. 2005;65:1822-9.

28. Bocca C, Bozzo F, Bassignana A, Miglietta A. Antiproliferative effects of COX-2 inhibitor celecoxib on human breast cancer cell lines. Mol Cell Biochem. 2011;350:59-70.

29. Zhu XG, Tao L, Mei ZR, Wu HP, Jiang ZW. Aspisol inhibits tumor growth and induces apoptosis in breast cancer. Exp Oncol. 2008;30: 289-94.

30. Robertson FM, Simeone AM, Mazumdar A, Shah AH, McMurray JS, Ghosh S, et al. Molecular and pharmacological blockade of the EP4 receptor selectively inhibits both proliferation and invasion of human inflammatory breast cancer cells. J Exper Ther Oncol. 2008;7:299-312.

31. Zhou J, Suzuki T, Kovacic A, Saito R, Miki Y, Ishida T, et al. Interactions between prostaglandin $\mathrm{E}(2)$, liver receptor homologue-1, and aromatase in breast cancer. Cancer Res. 2005;65: 657-63.

32. Subbaramaiah K, Howe LR, Bhardwaj P, Du B, Gravaghi C, Yantiss RK, et al. Obesity is associated with inflammation and 
elevated aromatase expression in the mouse mammary gland. Cancer Prev Res. 2011;4:329-46.

33. Bulun SE, Lin Z, Imir G, Amin S, Demura M, Yilmaz B, et al. Regulation of aromatase expression in estrogen-responsive breast and uterine disease: from bench to treatment. Pharmacol Rev. 2005;57:359-83.

34. Wolters R, Schwentner L, Regierer A, Wischnewsky M, Kreienberg R, Wockel A. Endocrine therapy in obese patients with primary breast cancer: another piece of evidence in an unfinished puzzle. Breast Cancer Res Treat. 2012;131:925-31.

35. McTiernan A, Wu L, Chen C, Chlebowski R, Mossavar-Rahmani $\mathrm{Y}$, Modugno F, et al. Relation of BMI and physical activity to sex hormones in postmenopausal women. Obesity. 2006;14:1662-77.

36. Hankinson SE, Willett WC, Manson JE, Hunter DJ, Colditz GA, Stampfer MJ, et al. Alcohol, height, and adiposity in relation to estrogen and prolactin levels in postmenopausal women. J Natl Cancer Inst. 1995;87:1297-302.

37. Cauley JA, Gutai JP, Kuller LH, LeDonne D, Powell JG. The epidemiology of serum sex hormones in postmenopausal women. Am J Epidemiol. 1989;129:1120-31.

38. Suzuki T, Miki Y, Ohuchi N, Sasano H. Intratumoral estrogen production in breast carcinoma: significance of aromatase. Breast Cancer. 2008;15:270-7.

39.• Subbaramaiah K, Morris PG, Zhou XK, Morrow M, Du B, Giri D, et al. Increased levels of COX-2 and prostaglandin E2 contribute to elevated aromatase expression in inflamed breast tissue of obese women. Cancer Discov. 2012;2:356-65. This study clearly links obesity with local COX-2 mediated inflammation and aromatase expression in human breast tissue. These findings greatly enhanced our understanding of one mechanism by which obesity may promote breast cancer risk and progression, providing a solid foundation for research regarding COX-2 inhibition in the obese patient population.

40. Morris PG, Hudis CA, Giri D, Morrow M, Falcone DJ, Zhou XK, et al. Inflammation and increased aromatase expression occur in the breast tissue of obese women with breast cancer. Cancer Prev Res. 2011;4:1021-9.

41. Hellmann J, Zhang MJ, Tang Y, Rane M, Bhatnagar A, Spite M. Increased saturated fatty acids in obesity alter resolution of inflammation in part by stimulating prostaglandin production. J Immunol. 2013;191:1383-92.

42. Nicklas BJ, Rogus EM, Colman EG, Goldberg AP. Visceral adiposity, increased adipocyte lipolysis, and metabolic dysfunction in obese postmenopausal women. Am J Physiol. 1996;270:E72-8.

43. Jensen MD, Haymond MW, Rizza RA, Cryer PE, Miles JM. Influence of body fat distribution on free fatty acid metabolism in obesity. J Clin Invest. 1989;83:1168-73.

44. Bjorntorp P, Bergman H, Varnauskas E. Plasma free fatty acid turnover rate in obesity. Acta Med Scand. 1969;185:351-6.

45. Fain JN. Release of interleukins and other inflammatory cytokines by human adipose tissue is enhanced in obesity and primarily due to the nonfat cells. Vitam Horm. 2006;74:443-77.

46. Maihofner C, Charalambous MP, Bhambra U, Lightfoot T, Geisslinger G, Gooderham NJ. Colorectal Cancer Group. Expression of cyclooxygenase-2 parallels expression of interleukin-1 beta, interleukin-6 and NF-kappaB in human colorectal cancer. Carcinogenesis. 2003;24:665-71.

47. Geng Y, Blanco FJ, Cornelisson M, Lotz M. Regulation of cyclooxygenase-2 expression in normal human articular chondrocytes. J Immunol. 1995;155:796-801.

48. Bowers LW, Maximo IX, Brenner AJ, Beeram M, Hursting SD, Price RS, et al. NSAID use reduces breast cancer recurrence in overweight and obese women: role of prostaglandin-aromatase interactions. Cancer Res. 2014;74:4446-57. While others have previously demonstrated that NSAID use is associated with lower breast cancer recurrence rates, this study was the first to suggest that obese and overweight estrogen receptor positive breast cancer patients may receive greater benefit from postdiagnostic NSAID use due to elevated local inflammation.

49. Bowers LW, Cavazos DA, Maximo IX, Brenner AJ, Hursting SD, deGraffenried LA. Obesity enhances nongenomic estrogen receptor crosstalk with the PI3K/Akt and MAPK pathways to promote in vitro measures of breast cancer progression. Breast Cancer Res. 2013; 15:R59.

50. Bowers LW, Brenner AJ, Hursting SD, Tekmal RR, deGraffenried LA. Obesity-associated systemic interleukin-6 promotes preadipocyte aromatase expression via increased breast cancer cell prostaglandin E2 production. Breast Cancer Res Treat. 2015;149: 49-57.

51. Holmes MD, Chen WY, Li L, Hertzmark E, Spiegelman D, Hankinson SE. Aspirin intake and survival after breast cancer. J Clin Oncol. 2010;28:1467-72.

52. Blair CK, Sweeney C, Anderson KE, Folsom AR. NSAID use and survival after breast cancer diagnosis in post-menopausal women. Breast Cancer Res Treat. 2007;101:191-7.

53. Valsecchi ME, Pomerantz SC, Jaslow R, Tester W. Reduced risk of bone metastasis for patients with breast cancer who use COX-2 inhibitors. Clin Breast Cancer. 2009;9:225-30.

54. Kwan ML, Habel LA, Slattery ML, Caan B. NSAIDs and breast cancer recurrence in a prospective cohort study. Cancer Causes Control. 2007;18:613-20.

55. Hudson AG, Gierach GL, Modugno F, Simpson J, Wilson JW, Evans RW, et al. Nonsteroidal anti-inflammatory drug use and serum total estradiol in postmenopausal women. Cancer Epidemiol Biomarkers Prev. 2008;17:680-7.

56. Sestak I, Distler W, Forbes JF, Dowsett M, Howell A, Cuzick J. Effect of body mass index on recurrences in tamoxifen and anastrozole treated women: an exploratory analysis from the ATAC trial. J Clin Oncol. 2010;28:3411-5. The authors show that obese postmenopausal women do not respond as well to anastrozole treatment, a finding with important clinical implications given the world-wide obesity epidemic.

57. Gnant M, Pfeiler G, Stoger H, Mlineritsch B, Fitzal F, Balic M, et al. The predictive impact of body mass index on the efficacy of extended adjuvant endocrine treatment with anastrozole in postmenopausal patients with breast cancer: an analysis of the randomised ABCSG-6a trial. Br J Cancer. 2013;109:589-96.

58. Folkerd EJ, Dixon JM, Renshaw L, A'Hern RP, Dowsett M. Suppression of plasma estrogen levels by letrozole and anastrozole is related to body mass index in patients with breast cancer. J Clin Oncol. 2012;30:2977-80.

59. Jonat W, Howell A, Blomqvist C, Eiermann W, Winblad G, Tyrrell $\mathrm{C}$, et al. A randomised trial comparing two doses of the new selective aromatase inhibitor anastrozole (Arimidex) with megestrol acetate in postmenopausal patients with advanced breast cancer. Eur J Cancer. 1996;32A:404-12.

60. Buzdar AU, Jones SE, Vogel CL, Wolter J, Plourde P, Webster A. A phase III trial comparing anastrozole (1 and 10 milligrams), a potent and selective aromatase inhibitor, with megestrol acetate in postmenopausal women with advanced breast carcinoma. Arimidex Study Group. Cancer. 1997;79:730-9.

61. Falandry C, Debled M, Bachelot T, Delozier T, Cretin J, Romestaing $\mathrm{P}$, et al. Celecoxib and exemestane versus placebo and exemestane in postmenopausal metastatic breast cancer patients: a double-blind phase III GINECO study. Breast Cancer Res Treat. 2009;116:501-8.

62. Chow LW, Yip AY, Loo WT, Lam CK, Toi M. Celecoxib antiaromatase neoadjuvant (CAAN) trial for locally advanced breast cancer. J Steroid Biochem Mol Biol. 2008;111:13-7.

63. Dirix LY, Ignacio J, Nag S, Bapsy P, Gomez H, Raghunadharao D, et al. Treatment of advanced hormone-sensitive breast cancer in 
postmenopausal women with exemestane alone or in combination with celecoxib. J Clin Oncol. 2008;26:1253-9.

64. Martin LA, Davies GL, Weigel MT, Betambeau N, Hills MJ, Salter $\mathrm{J}$, et al. Pre-surgical study of the biological effects of the selective cyclo-oxygenase-2 inhibitor celecoxib in patients with primary breast cancer. Breast Cancer Res Treat. 2010;123:829-36.

65. Del Fabbro E, Parsons H, Warneke CL, Pulivarthi K, Litton JK, Dev R, et al. The relationship between body composition and response to neoadjuvant chemotherapy in women with operable breast cancer. Oncologist. 2012;17:1240-5.

66. Chen S, Chen CM, Zhou Y, Zhou RJ, Yu KD, Shao ZM. Obesity or overweight is associated with worse pathological response to neoadjuvant chemotherapy among Chinese women with breast cancer. PLoS One. 2012;7:e41380.

67. Litton JK, Gonzalez-Angulo AM, Warneke CL, Buzdar AU, Kau SW, Bondy M, et al. Relationship between obesity and pathologic response to neoadjuvant chemotherapy among women with operable breast cancer. J Clin Oncol. 2008;26:4072-7.

68. Pajares B, Pollan M, Martin M, Mackey JR, Lluch A, Gavila J, et al. Obesity and survival in operable breast cancer patients treated with adjuvant anthracyclines and taxanes according to pathological subtypes: a pooled analysis. Breast Cancer Res. 2013;15:R105.
69. de Azambuja E, McCaskill-Stevens W, Francis P, Quinaux E, Crown JP, Vicente M, et al. The effect of body mass index on overall and disease-free survival in node-positive breast cancer patients treated with docetaxel and doxorubicin-containing adjuvant chemotherapy: the experience of the BIG 02-98 trial. Breast Cancer Res Treat. 2010;119:145-53.

70. Chow LW, Tung SY, Ng TY, Im SA, Lee MH, Yip AY, et al Concurrent celecoxib with 5-fluorouracil/epirubicin/cyclophosphamide followed by docetaxel for stages II - III invasive breast cancer: the OOTR-N001 study. Expert Opin Investig Drugs. 2013;22:299 307.

71. Fabi A, Metro G, Papaldo P, Mottolese M, Melucci E, Carlini P, et al. Impact of celecoxib on capecitabine tolerability and activity in pretreated metastatic breast cancer: results of a phase II study with biomarker evaluation. Cancer Chemother Pharmacol. 2008;62: 717-25.

72. Pierga JY, Delaloge S, Espie M, Brain E, Sigal-Zafrani B, Mathieu $\mathrm{MC}$, et al. A multicenter randomized phase II study of sequential epirubicin/cyclophosphamide followed by docetaxel with or without celecoxib or trastuzumab according to HER2 status, as primary chemotherapy for localized invasive breast cancer patients. Breast Cancer Res Treat. 2010;122:429-37. 